\title{
EMOJIS COMO ESTRATÉGIAS DE REPARO EM PEDIDOS DE DESCULPAS: UM ESTUDO SOBRE CONVERSAS EM AMBIENTE DIGITAL
}

\section{EMOJIS AS STRATEGIES OF REPAIR IN APOLOGIES: A STUDY ON DIGITAL COMMUNICATION EXCHANGES}

\section{Ana Larissa Adorno Marciotto Oliveira* Gustavo Ximenes Cunha* Fernanda Teixeira Avelar ${ }^{* *}$}

\section{RESUMO}

Os emojis estão ligados à expressão emotiva, bem como à identificação do ato de fala prevalente na troca comunicativa em ambiente digital. Nessa perspectiva, este estudo alinhase à noção de que esses ícones possam salientar a força ilocucionária de um determinado ato de fala (DRESNER; HERRING, 2010, AVELAR, 2018), mais particularmente, o pedido de desculpas perante recusas (KERBRAT-ORECCHIONI, 2001, LEECH, 2014). Para verificar a validade dessa proposta, este estudo foi realizado por meio da análise de 432 threads contendo emojis, coletados em interações ocorridas em um grupo de WhatsApp (AVELAR, 2018). Os resultados apontam que os emojis constituem estratégia de reparo, restaurando a imagem do ofensor e do ofendido. Essas estratégias são empregadas para reconquistar uma possível perda de face, resultante da realização de um ato de fala despreferido, como a recusa.

Palavras-chave: pedidos de desculpa; estratégias de reparo; emoji.

\section{ABSTRACT}

Emojis are linked to the emotive expression, as well as to the identification of the prevailing speech act in a communicative exchange carried in the digital environment. From this perspective, this study is in line with the notion that these icons may be used to highlight the illocutionary force of a given speech act (DRESNER, HERRING, 2010, AVELAR, 2018), more specifically, the apologies following refusals, (KERBRAT-ORECCHIONI, 2001, LEECH, 2014). To verify the validity of this proposal, we carried the analysis of 432 threads containing emojis, collected from interactions within a WhatsApp group (AVELAR, 2018). The results point out that emojis constituted a strategy of repair, used to restore the image of the offender and that of the offended. These strategies also served as repairs, due to the potential face loss resulting from the accomplishment of a dispreferred speech act, such as refusals.

Keywords: apologies; strategies of repair; emoji.

\footnotetext{
* Universidade Federal de Minas Gerais, Belo Horizonte (MG). Brasil. adornomarciotto@gmail.com ** Universidade Federal de Minas Gerais, Belo Horizonte (MG). Brasil. ximenescunha@yahoo.com.br *** Universidade Federal de Minas Gerais, Belo Horizonte (MG). Brasil. fe2509@hotmail.com
} 


\section{VISÃO GERAL DO ESTUDO}

O emprego massivo de emojis na comunicação digital foi amplamente registrado, por exemplo, pelo Dicionário Oxford (Oxford Dictionary), que elegeu o ícone chamado de face withtearsofjoy ( $\Theta$ - carinha com lágrimas de alegria) como a palavra do ano de 2015. A esse respeito, Evans (2017) afirma que, em 2016, 3,2 bilhões de pessoas já tinham acesso regular à Internet e que $75 \%$ desses usuários a acessavam via Smartphones. O estudo de Evans (2017) aponta ainda números expressivos quanto ao uso de emojis, estimando que, a cada dia, mais de 6 bilhões de emojis sejam trocados nas várias mídias digitais existentes.

Outros estudos no campo da linguagem foram também propostos para descrever o potencial dos emojis na comunicação digital (c.f. EVANS, 2015, PAIVA 2016, OLIVEIRA; CARNEIRO, 2018, entre outros). Particularmente, o estudo de Evans (2017) interessa a esta pesquisa, pois o autor defende que a força comunicativa desses ícones ocorre em razão de estarem associados a elementos interpessoais da linguagem.

Os emojis atuam também como índices de informalidade, uma vez que, em registros menos formais, os usos abreviados da linguagem e os textos contendo menos materialidade linguística tendem a ser mais frequentemente encontrados (EVANS, 2017). Na comunicação digital, essa economia de material linguístico, operada via uso de emojis, implica, algumas vezes, que o cálculo do significado de um thread' seja efetuado por meio da relação de intimidade e de pertencimento a um grupo, ou seja, baseado no conhecimento compartilhado por seus membros.

Com respeito a esse cálculo de sentido, e tendo como base os fundamentos da Teoria da Relevância, um enunciado pode ser entendido como uma "indicação esquemática" do significado intencional de um determinado falante (WILSON, SPERBER, 2012, p. 13). Nesse sentido, quanto mais indireto um significado central for, mais trabalho inferencial o interlocutor precisará realizar para interpretá-lo (WILSON, SPERBER, 2012), podendo o uso de emojis, se esse uso for possível, colaborar nessa tarefa.

Na comunicação digital, portanto, os emojis estão ligados à expressão emotiva, bem como à identificação do ato de fala prevalente na troca comunicativa. Diante disso, este estudo alinha-se à ideia de que esses ícones possam salientar a força ilocucionária de um determinado ato de fala (DRESNER; HERRING, 2010, AVELAR, 2018). Neste estudo em particular, o ato de fala a ser analisado é o pedido

1. O termo thread refere-se aqui a grupo de textos interconectados na Internet, no qual os interactantes estejam discutindo um assunto específico (EVANS, 2017). 
de desculpas diante de recusas. Os pedidos de desculpas foram considerados atos de fala particularmente adequados para esta investigação, pois constituem ameaças específicas de face, no sentido empregado por Brown e Levinson (1987)². Em nossos dados, esses pedidos estavam quase sempre acompanhados de emojis. Interessa-nos, assim, compreender o papel desses ícones nesse tipo de interação.

Propomos, então, que a construção do contexto interacional digital seja um processo inferencial (WILSON; SPERBER, 2012), no qual os emojis atuam como pistas inferenciais e/ou como elementos de orientação para a compreensão do ato de fala, nesse caso o pedido de desculpas diante de recusas, em foco em um thread. Para verificar a validade dessa proposta, este estudo foi realizado por meio da análise de 432 threads contendo emojis, coletados em interações ocorridas em um grupo de WhatsApp (AVELAR, 2018). Os threads contendo emojis foram manualmente analisados e, em seguida, procedeu-se à análise dos pedidos de desculpa e das recusas, seguidos de suas respectivas sequências de reparo.

A seguir, passaremos ao referencial teórico que fundamenta esta pesquisa. Nosso referencial teórico será apresentado em dois momentos. Inicialmente, exporemos as características centrais dos emojis. Em seguida, abordaremos os atos de fala pedido de desculpas e recusa, focalizando em espacial o pedido de desculpas. Feita a apresentação do referencial teórico, realizaremos as análises das funções dos emojis presentes em nosso corpus.

\section{AS FUNÇÕES DISCURSIVO-PRAGMÁTICAS DOS EMOJIS}

Os emojis são imagens de personagens (picture characters) produzidas no Japão na década de 90 e destinadas ao uso em dispositivos móveis de telefonia. Recentemente, eles vêm se tornando presentes em praticamente todo o mundo, sendo utilizados em mensagens de texto de mídias sociais variadas. Essa popularização também coincidiu com a expansão no uso dos chamados Smartphones (telefones móveis com acesso à internet).

Em contraste com os emoticons, que são criados por meio de uma sequência de caracteres ortográficos, os emojis são representados por caracteres do padrão

2. Em Brown e Levinson (1987, p. 61), a face negativa corresponde à "reivindicação básica de territórios, de preservação pessoal, de direitos a não-distração - i.e. de liberdade de ação e liberdade de imposição", enquanto a face positiva corresponde à "autoimagem consistente e positiva ou 'personalidade' (crucialmente incluindo o desejo de que essa autoimagem seja apreciada e aprovada) reivindicada pelos interactantes". Os atos podem ser ameaçadores (Face Threatening Acts - FTA) para a face negativa do locutor (ex. promessa) e do interlocutor (ex. ordem) e para a face positiva do locutor (ex. pedido de desculpas) e do interlocutor (ex. crítica). 
UNICODE ${ }^{3}$. Os caracteres do tipo emoji incluem não apenas faces, mas também conceitos e ideias ligados ao clima, a veículos, a edifícios, à comida e à bebida, bem como a atividades esportivas, familiares e profissionais em geral (PAVALANATHAN, EISENSTEIN, 2015).

Em análise comparativa sobre o uso de emoticons e de emojis, Pavalanathan e Eisenstein (2015) demonstram que os usuários que adotam os emojis tendem a empregar menos emoticons. Esse resultado indica que os emojis estão substituindo essa forma particular de comunicação digital, paralinguística e ortográfica, por uma comunicação pictográfica, ou icônica.

A função primária dos emoticons e dos emojis está ligada à expressão de emoção. Dessa forma, esses ícones são usados na comunicação digital com o intuito de reproduzir as pistas não verbais presentes da interação face a face (CRYSTAL 2006, DRESNER, HERRING, 2010). Vários estudos, no entanto, vão além dessa compreensão, indicando que a função discursiva dos emoticons e dos emojis pode ultrapassar a expressão de emoção ou de atitude e contribuir para indicar como os atos de fala aos quais eles se associam devem ser interpretados (DRESNER; HERRING, 2010).

Em seu estudo, Dresner e Herring (2010) identificaram três funções discursivopragmáticas básicas dos emoticons: (1) indicação de emoção, convencionalmente ligada às expressões faciais (por exemplo, a 'carinha feliz' ou a 'carinha triste'); (2) expressão de significado não emocional, também convencionalmente veiculada por meio de expressões faciais (por exemplo, a 'carinha pensativa') e (3) indicação, ou reforço, da força ilocucionária dos atos de fala ao quais os emojis se associam. Essa função (3) não é necessariamente representada por expressões faciais, mas pode ser feita dessa forma também, por exemplo, por meio de um 'sorriso', usado para reforçar um pedido, bem como para atenuar a potencial ameaça que um ato de fala representa para as faces em jogo na interação.

Ainda acerca do aspecto discursivo-pragmático dos emojis, Kelly e Watts (2015) entrevistaram um conjunto culturalmente diversificado de participantes sobre o uso de emojis em trocas interacionais entre pessoas próximas. $\mathrm{O}$ estudo revelou que, além da expressão de emoções, os emojis foram utilizados também com outros propósitos, por exemplo, para manter ou reforçar o pertencimento a um grupo social específico e/ou para favorecer a interpretação dos sentidos comunicados nos threads. Eles também serviram para criar um ambiente lúdico,

3. O UNICODE é um padrão que permite aos computadores representar e manipular, de forma consistente, textos de qualquer sistema de escrita existente. 
gerando o que os autores caracterizaram como sendo um tipo de "singularidade compartilhada", vigente em um grupo particular de interactantes digitais.

Neste estudo, ao analisarmos threads contendo emojis, verificamos que as funções pragmático-discursivas que eles desempenham são bastante salientes. Com relação a essas funções, Paiva (2016) as sistematiza, observando que esses ícones são comumente empregados das seguintes maneiras ${ }^{4}$ :

Para substituir palavras.

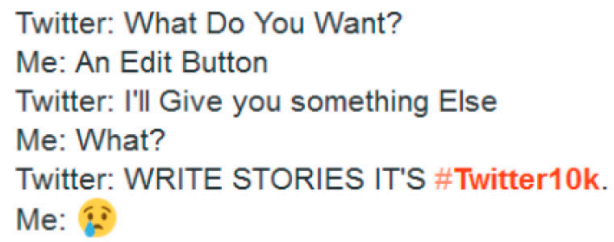

Para expressar emoção.

\#AfterTheNovemberElection we may all be able to write essays on Twitter about how we feel about it No000000000000! \#Twitter10k

Facebook orkutizou. Agora Twitter facebookeando. Medo. $\because \#$ \#witter10k

Para indicar afeto.

Que gostosura!

Muito linda dua netinha !!!! Parabéns vovó !!!!! \& \&

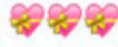

Que lindinha!

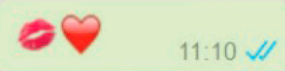

4. Todos os exemplos apresentados neste item foram extraídos de Paiva (2016, p. 393-395). 
Como intensificadores.

Would be annoying if ppl will post a $10 \mathrm{k}$ character tweet!! SAY NO to \#Twitter10k 용으

Para expressar ironia.

I guess we can start submitting our papers and essays by tweeting them to our professor's hashtag, yeah? A\#\#Titter10k

Complementando o estudo de Paiva (2016) e alinhando-se ao estudo de Dresner e Herring (2010), Avelar (2018) revelou que os emojis funcionam como intensificadores de conteúdo emotivo, bem como atuam como estratégias de preservação de face (BROWN, LEVINSON, 1978, 1987), mitigando ameaças potenciais comunicadas em um determinado thread.

Tendo em vista o papel interacional dos emojis na comunicação digital, nosso intuito, como evidenciado na Introdução, é investigar o significado desses elementos como pistas para a interpretação do ato de fala em foco em um thread, em particular, o ato de fala caracterizado como pedido de desculpas após uma recusa. Por isso, antes de revelarmos as funções desempenhadas pelos emojis em nosso corpus, faremos uma caracterização dos atos de fala pedido de desculpas e recusa, focalizando, sobretudo, o pedido de desculpas.

\section{POR UMA CARACTERIZAÇÃO DAS RECUSAS E DOS PEDIDOS DE DESCULPA}

$\mathrm{Na}$ literatura sobre im/polidez, as recusas (refusals) são consideradas atos de fala ameaçadores de face (FTA, c.f. nota 2). Ao recusar, o falante produz uma resposta não-marcada, despreferida e não esperada a uma oferta ou convite (BROWN, LEVINSON, 1987). Recusas são, por essa razão, formalmente mais complexas, contendo mais material linguístico (GIVÓN, 2014). Isso se deve ao fato de que, de acordo com Shishavan e Sharifian (2016), as recusas constituem uma forma de desaprovação ou de desrespeito ao interlocutor. Afinal, aquele que recusa um convite, por exemplo, reage a um ato lisonjeiro para a sua face positiva (o convite) com um ato ameaçador para a face positiva do interlocutor (a recusa) . $^{5}$

5. Opondo-se à proposta de Brown e Levinson (1987) de que todos os atos de fala seriam ameaçadores, Kerbrat-Orecchioni $(1992 ; 2006)$ e Leech (2014) defendem que atos como agradecimento, oferta, convite, elogio seriam lisonjeiros para a face de quem os recebe e teriam, assim, um caráter antiameaçador. 
Por essa razão, a elaboração das recusas geralmente envolve negociações ampliadas, bem como a solicitação por cooperação verbal, ou seja, costumam apresentar uso extensivo de estratégias de preservação de face.

Diante do grau de agressividade que representam para as faces dos interactantes, as recusas, em nossa sociedade, costumam ser acompanhadas de pedidos de desculpas. Os pedidos de desculpas têm sido objeto de análise de vários estudos, por diferentes correntes teórico-metodológicas. Em abordagens filosóficas (AUSTIN, 1990[1962], SEARLE 1969), linguísticas (BLUM-KULKA et al. 1989; TROSBORG, 1995; AIJMER 1996; ROBINSON 2004; LEECH, 2014; HERITAGE; RAYMOND, 2016; LUTZKY; KEHOE, 2017) e sociológicas (GOFFMAN, 1973, WERNECK, 2012), os estudiosos têm revelado o interesse desse ato para a compreensão do modo como os encontros sociais se estruturam e do papel da linguagem nessa estruturação. Na perspectiva linguística (pragmática), considerando a Teoria dos Atos de Fala como fundamento central (AUSTIN, 1990[1962]), Holmes (1990, p. 27) caracteriza o pedido de desculpas nos seguintes termos:

Um pedido de desculpas é um ato de fala endereçado às necessidades de $\mathrm{B}$ e tencionado a reparar uma ofensa pela qual $\mathrm{A}$ assume a responsabilidade e, então, pretende restaurar o equilíbrio entre A e B (em que A é o que pede desculpas; e B é a parte ofendida).

Ainda com relação à caracterização de pedidos de desculpas, Lakoff (2001) salienta a potencial dificuldade de reconhecer esses pedidos, pois eles variam entre formulações canonicamente explícitas até formulações ambíguas mais indiretas, ou seja, mais próximas de explicações e de justificativas. Mas, na literatura sobre esse ato de fala, é consensual a percepção de que o pedido de desculpas é um ato de fala (ou evento de fala ${ }^{6}$ ) que está associado à realização de um ataque ou uma ofensa e, por isso, constitui um "ato pelo qual um locutor busca fazer com que seu destinatário lhe outorgue o perdão por uma 'ofensa' de que ele é, de alguma forma, o responsável" (KERBRAT-ORECCHIONI, 2001, p. 124). Como revela essa definição, bem como a de Holmes expressa anteriormente, a maior parte

Dessa forma, para esses autores, os atos de fala seriam divididos em dois grandes grupos: o dos Face Threatening Acts e o dos Face Flattering Acts.

6. Leech (2014) opta por chamar a desculpa de evento de fala (speech event), tendo em vista o fato de que a prática de desculpar-se raramente se resume à realização de um único ato. $\mathrm{O}$ mais comum é o ato central da desculpa (head act (BLUM-KULKA; OSHSTAIN, 1984) ser antecipado ou seguido por vocativos explicitando a quem a desculpa é endereçada, por justificativas para a realização da ofensa, por sentenças condicionais relativizando a responsabilidade do ofensor etc. Dessa forma, "as desculpas são parte de um complexo de atos individuais ou intervenções" (LEECH, 2014, p. $115)$. 
dos estudos sobre o pedido de desculpas investiga as desculpas realizadas pelo próprio ofensor, como ocorre na maioria das desculpas identificadas em interações cotidianas.

Para o estudo do pedido de desculpas, a natureza da ofensa é um fator importante, na medida em que ela tem impacto tanto sobre a elaboração da desculpa, quanto sobre sua recepção junto à parte ofendida, cuja face necessita de reparos. Assim, nas interações que ocorrem em estabelecimentos comerciais, em reuniões familiares ou no ambiente de trabalho, as desculpas costumam ser motivadas por ofensas rituais ou incidentes ligados às normas que estruturam e regulam a "ordem da interação" (GOFFMAN, 1983). Por isso, costumam ser aceitas pela parte ofendida, que, não raro, como resposta preferida, minimiza a gravidade da ofensa que motivou o pedido de desculpas (KERBRAT-ORECCHIONI, 2001, LEECH, 2014).

Já no mundo político e religioso, por exemplo, tendo em vista a dimensão das ofensas que obrigam uma figura política a se desculpar em público (genocídios, torturas, prisões arbitrárias, corrupção, casos de assédio moral ou sexual, violações de acordos humanitários etc.), as desculpas geralmente são consideradas insuficientes pela parte ofendida, e a forma como a desculpa foi realizada (se a figura pública se responsabilizou de fato pela ofensa) costuma ser motivo de intensos debates na mídia (KAMPF, 2008, 2009).

Conforme Meier (1998), os estudos sobre as funções dos pedidos de desculpa ou são voltados para a compreensão dos efeitos da desculpa sobre o locutor (abordagens speaker-supportive) ou são voltados para a compreensão dos efeitos da desculpa sobre o interlocutor (bearer-supportive). Nos últimos anos, os resultados de estudos sobre esse ato de fala, seja centrando a atenção em um dos dois interlocutores, seja focalizando ambos, revelam que a desculpa é uma estratégia útil, sobretudo, para restaurar ou reparar a face tanto do ofensor quanto do ofendido, tendo em vista que esse ato possui uma dimensão essencialmente moral (MEIER, 1998, KERBRAT-ORECCHIONI, 2001, HARRIS; GRAINGER; MULLANY, 2006, KAMPF, 2008, 2009, LEECH, 2014).

Nessa perspectiva, a atitude ou a postura que os interactantes tomam com o propósito de solucionar um impasse, ou de prevenir que este ocorra, foi denominada por Meier (1995) como Trabalho de Reparo (Repair Work). De acordo com a autora, o trabalho de reparo relaciona-se às estratégias linguísticas empregadas para a compensação de possíveis danos à imagem (ou à face) dos interactantes. O Trabalho de Reparo é conduzido mediante "um vínculo estabelecido entre os interlocutores 
quando eles agem verbalmente de forma não esperada, ou abaixo das expectativas para a interação em questão" (MEIER, 1995, p. 381).

Mais especificamente, do ponto de vista do locutor (abordagens speakersupportive), a realização da desculpe permite a ele reparar a ofensa cometida, reconhecer-se responsável pela ofensa, reconhecer que violou normas sociais implícitas e demonstrar que, embora tenha violado essas normas, ele as respeita. Já do ponto de vista do interlocutor (abordagens hearer-supportive), a realização da desculpa o auxilia a se ver como merecedor da estima e do respeito do locutor e como um indivíduo cujos desejos de face devem ser respeitados e considerados. Nesse sentido, o pedido de desculpas entraria na categoria dos atos lisonjeiros para a face (Face Flattering Acts) (KERBRAT-ORECCHIONI, 1992, 2006, LEECH, 2014).

Porém, são, em especial, os estudos sobre a realização dos pedidos de desculpas no mundo político que revelam que as desculpas, mesmo as realizadas em situações menos formais, não devem ser consideradas como simples atos lisonjeiros para a face, como convites e cumprimentos, tendo em vista as consequências negativas que podem ter para a imagem do ofensor. Afinal, quem se desculpa reconhece que cometeu uma falta ou que não foi capaz de evitá-la e que está em débito com a parte ofendida, a quem precisa pedir perdão. Assim, quem se desculpa reconhece uma culpa e admite incapacidades ou a realização de comportamentos inadequados e ofensivos, o que, no caso das desculpas realizadas no mundo político, implica perda de credibilidade junto à população (eleitorado) e, em último caso, significa a "morte política" do ofensor.

Por isso, a realização de pedidos de desculpa costuma se caracterizar pela indiretude, pela falta de clareza, pelo excesso de justificativas e pela minimização de responsabilidades, sendo objeto de controvérsias. Ao tratar de pedidos de desculpas realizados por figuras públicas, Kampf (2009, p. 2259-2260) observa: "se elas [figuras públicas] escolhem realizar uma desculpa, devem decidir sobre as estratégias pragmáticas que são as mais adequadas para apaziguar a face da vítima, sem realizar um ataque perigoso para sua própria face".

Nessa perspectiva, o estudo da forma das desculpas implica o estudo de suas funções. Do ponto de vista formal, as desculpas podem ser diretas e indiretas. As desculpas diretas costumam se constituir de expressões performativas, construções formulaicas e enunciados no imperativo: "me desculpe", "desculpa", "queira me desculpar", "perdão", "me perdoe" etc. Essas formas podem ser acompanhadas de modificadores internos ("mil desculpas", "me perdoem mesmo"), sintaticamente integrados ao ato central (head act (BLUM-KULKA; OSHSTAIN, 1984)), e de 
modificadores externos (indicação das razões da ofensa), não inseridos no ato central.

Quanto às desculpas indiretas, elas costumam expressar a falta de intenção do ofensor em cometer a ofensa ("Não foi minha intenção") ou seu estado de espírito ("lamento profundamente", "estou profundamente envergonhada/o"). Podem ser formadas ainda por oferecimento de reparações, justificativas ou explicações sobre os motivos que levaram o ofensor a cometer a ofensa. Na literatura sobre o pedido de desculpas, não há um consenso acerca da natureza das justificativas. Assim, Blum-Kulka e Olshtain (1984) e Kerbrat-Orecchioni (2001), por exemplo, consideram as justificativas como uma forma indireta de desculpas. Já Leech (2014) considera que as justificativas, assim como reconhecimentos de responsabilidade e oferecimentos de reparações, seriam constituintes satélites (modificadores externos) que intensificariam ou mitigariam o valor ilocucionário da desculpa expressa pelo ato central do evento de fala (c.f. nota 6). Neste trabalho, consideramos que as justificativas são uma forma indireta de desculpa, já que uma afirmação como "O trânsito estava um horror!" dita por uma pessoa que chega atrasada a uma reunião constitui uma forma indireta de "Me desculpem pelo atraso!".

Autores como Kerbrat-Orecchioni (2001) e Kampf (2008, 2009) apontam uma correlação entre o grau de gravidade da ofensa e a forma mais ou menos direta e explícita da desculpa. Assim, nas interações de que participam interlocutores entre os quais não se verifica assimetria acentuada de poder (amigos, colegas de trabalho, parentes), as ofensas costumam se caracterizar por um grau de agressividade baixo para a face do ofendido. Por isso, nessas interações, as desculpas costumam ser diretas e pouco desenvolvidas. Já nas interações que se definem por assimetrias acentuadas de poder entre os interlocutores e naquelas de que participam figuras públicas e que envolvem parcelas amplas da população, as ofensas costumam ser altamente agressivas para a face ou imagem pública não de um indivíduo apenas, mas de segmentos de populações ou mesmo de populações inteiras. Nessas interações, as desculpas costumam ser excessivamente indiretas ou acompanhadas de muitas justificativas relativizando a responsabilidade do locutor pela ofensa. Por isso, essas desculpas são vistas com desconfiança pela parte ofendida, já que seriam uma evidência de que o ofensor não apresenta desculpas sinceras ou se responsabiliza pouco pela ofensa (KAMPF, 2008, 2009).

Como veremos no próximo item, consideramos os emojis como modificadores externos (não inseridos no ato central) que acompanham pedidos de desculpas tanto diretos, quanto indiretos. Isso porque eles constituem recursos da comunicação digital que permitem ao ofensor ou, no caso do nosso corpus, ao participante da 
interação que recusa um convite evidenciar que sua ação de romper uma norma social (a recusa) lhe causa tristeza, desconforto ou constrangimento. Nesse sentido, o emoji, na comunicação digital, desempenha um papel proxêmico de primeira importância, tendo em vista a impossibilidade, nas interações por WhatsApp que estudamos, de os interlocutores se valerem de expressões faciais, como ocorre nas interações face a face, para expressarem proximidade, afeto ou deferência.

\section{0 EMPREGO DOS EMOJIS EM THREADS CONTENDO PEDIDOS DE DESCULPA}

Faz parte de todos os threads componentes do nosso corpus um convite feito por um dos interlocutores. Em reação a esse convite, os interlocutores de cada thread deram respostas preferidas (aceite) ou despreferidas (recusa). Tendo em vista nossos objetivos neste trabalho, focalizamos apenas as respostas despreferidas.

Como exposto, a recusa a um convite representa uma ameaça à face do responsável pelo convite. Por isso, a maior parte das recusas identificadas se constituiu apenas do pedido de desculpas formulado de forma indireta (justificativas) e seguido do emoji (carinha triste). Nesses threads, a ausência de uma recusa explícita constitui uma estratégia importante de polidez $z^{7}$. Já nos threads em que há recusas explícitas, os próprios pedidos de desculpas atuam como estratégias de polidez, na medida em que contribuem para revelar que aquele que recusa um convite reconhece que infringiu uma norma social e que, consequentemente, agrediu a face do autor do convite, agressão que necessita de reparos. Também nesses casos, o pedido de desculpas é formulado predominantemente de forma indireta (justificativas) e é seguido do emoji (carinha triste). Dessa forma, em todas as recusas (explicitas ou não), verificou-se a presença constante de emojis atuando como estratégia de reparo, por expressar lamento pela impossibilidade de aceitar o convite, mitigando uma possível ameaça à face positiva do autor do convite e, ao mesmo, tempo, assegurando a imagem esperada do ofensor para a ocasião.

A seguir, para que se verifique de maneira mais detalhada o papel dos emojis, abordamos, inicialmente, os pedidos de desculpas que sucedem recusas explícitas e, em seguida, os pedidos de desculpas que ocorrem sem uma recusa explícita ${ }^{8}$.

\footnotetext{
7. Em Brown e Levinson (1987), a não realização de um FTA, enquanto uma das cinco superestratégias propostas pelos autores, constitui uma espécie de grau máximo de polidez, ainda que, dependendo do contexto, possa ter como efeito inviabilizar a comunicação (CUNHA; RUFINO, 2018).

8. Nos exemplos apresentados, nomes dos interlocutores e de seus locais de trabalho estão ocultos, para preservar o anonimato dos interlocutores.
} 


\section{PEDIDOS DE DESCULPAS APÓS RECUSAS EXPLÍCITAS}

O exemplo (1) é representativo de recusas explícitas seguidas de pedidos de desculpas, potencializados pelo uso de emojis (carinha triste).

(Exemplo 1)

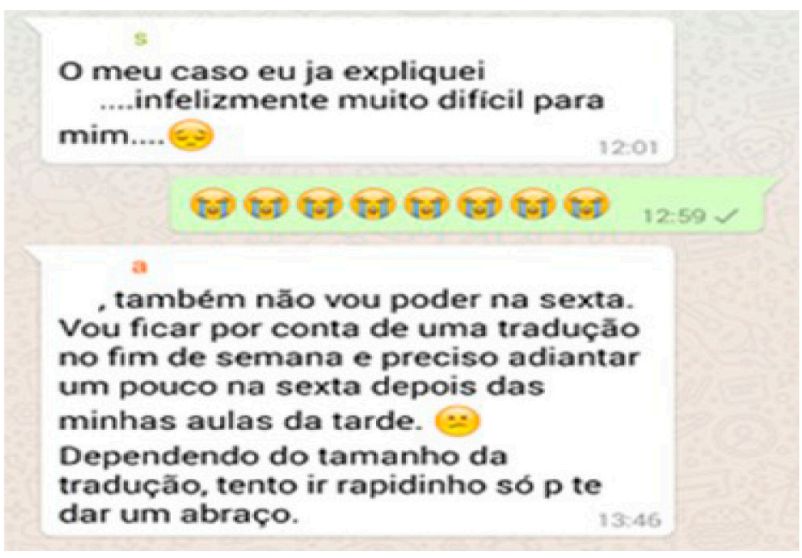

Nesse thread, há duas recusas que apresentam estruturas semelhantes. Ambas se compõem de uma recusa explícita seguida de um pedido de desculpas indireto. $\mathrm{Na}$ primeira recusa, esta é formulada pela retomada de recusa já expressa anteriormente ("O meu caso eu já expliquei"). Na segunda recusa, esta é formulada diretamente ("também não vou poder na sexta"). Após as duas recusas, elaboram-se pedidos de desculpas indiretos, na forma de justificativa ou de explicação, nos quais o emoji (carinha triste) atua para expressar descontentamento e embaraço pela recusa ao convite. Esses pedidos de desculpas funcionam como estratégias de polidez que visam a atenuar o grau de agressividade das recusas.

No que se refere aos pedidos de desculpas, vale chamar a atenção para a diferença na forma como cada pedido foi elaborado. No primeiro ("...infelizmente muito difícil para mim..."), o locutor, com o emoji, reforça o estado de espírito expresso pelo advérbio "infelizmente". Tanto o advérbio quanto o emoji atuam como modalizadores que, emoldurando o pedido de desculpas indireto ("muito difícil para mim..."), auxiliam o locutor a reivindicar para si a imagem de alguém que lamenta (se entristece por) romper uma norma social esperada e que reconhece sua culpa.

No segundo pedido de desculpas, estas são formuladas de forma indireta, por meio de justificativas ("Vou ficar por conta de uma tradução [...]"). Nesse pedido, o emoji é o único modalizador das justificativas para a recusa. Sem o emoji, as 
desculpas, ainda que indiretas, poderiam parecer excessivamente ríspidas aos olhos do interlocutor, já que o locutor não lamenta sua indisponibilidade e implicitamente cria uma escala de importância entre trabalho e amigos. Mas, com o emoji, o locutor se representa na interação como alguém que, embora coloque o trabalho em primeiro lugar, lamenta-se por isso. Desse modo, observa-se o uso de estratégias que projetam a face do interactante para atenuar a ameaça que uma recusa pode causar à sua imagem perante o ouvinte/leitor e perante o grupo. Esses elementos caracterizam, assim, a sequência recusa + pedido de desculpa indireto, contendo estratégia de reparo com justificativa e emoji.

\section{PEDIDOS DE DESCULPAS SEM RECUSAS EXPLÍCITAS}

Como exposto, na maior parte dos threads do corpus, verifica-se apenas o pedido de desculpas acompanhado de emojis, sendo a recusa implícita. É o que revelam os exemplos (2) e (3).

(Exemplo 2)

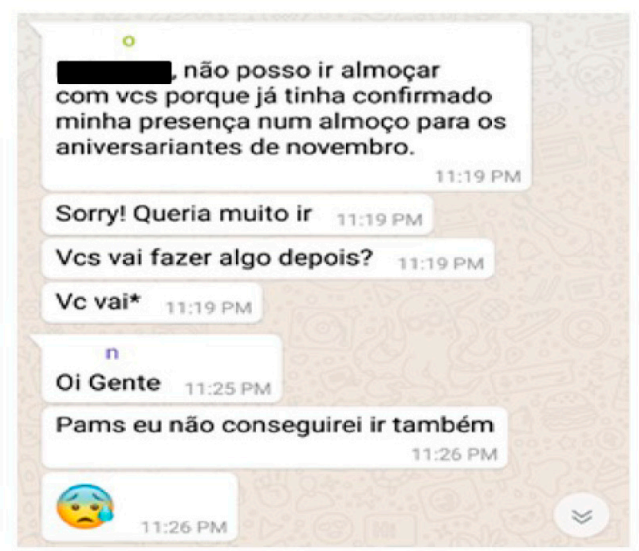




\section{(Exemplo 3)}

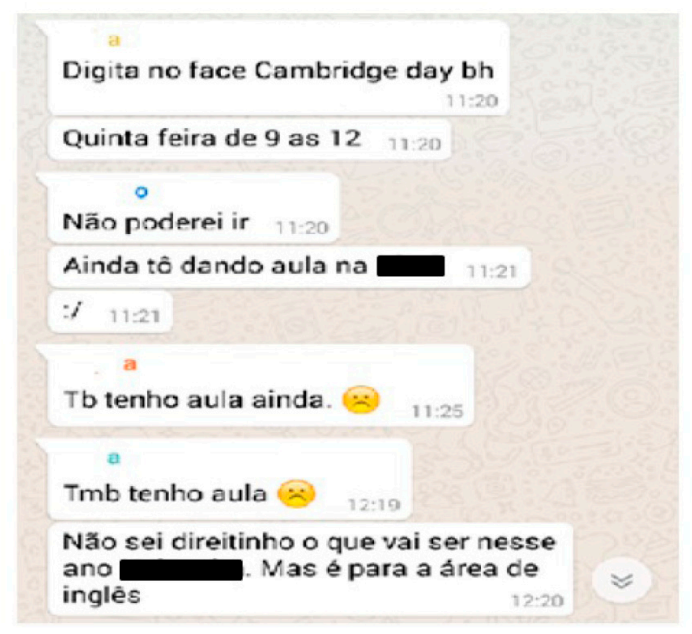

Nesses threads, os locutores que utilizam os emojis (carinha chorando e carinha triste) não recusam explicitamente o convite, optando por produzir apenas pedidos de desculpas indiretos, seguidos de ocorrências dos emojis. Enquanto modificadores externos, esses emojis modalizam as desculpas, revelando que os locutores (ofensores) entendem que a impossibilidade de comparecer ao evento é uma ofensa à face positiva do autor do convite ou ao seu desejo de ser apreciado e aprovado na interação (BROWN ; LEVINSON, 1987), ofensa que devem lamentar e pela qual devem se mostrar consternados. Sem os emojis, os pedidos de desculpas, mesmo indiretos, poderiam ser entendidos como grosseiros pela pessoa ofendida, que se veria como não merecedora de consideração.

O papel do emoji como modalizador em reações formadas apenas por pedidos de desculpas, sem uma recusa explícita, fica ainda mais evidente no exemplo (4). 
(Exemplo 4)

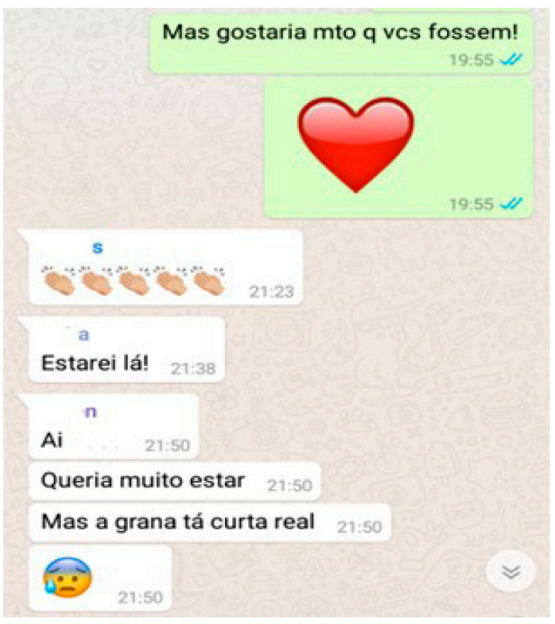

Nesse thread, o convite é seguido de três reações: dois aceites e um pedido de desculpas. No pedido de desculpas ("Ai Queria muito estar Mas a grana tá curta real $\because$ "), não há uma recusa explícita, tal como ocorre no exemplo (1). O locutor opta por elaborar apenas um pedido de desculpas indireto (justificativas pela ausência), pedido que é emoldurado por uma interjeição (Ai) e pelo emoji (carinha chorando).

O interesse desse pedido de desculpas está no acúmulo de estratégias de polidez empregadas pelo locutor. Como exposto no item anterior, desculpar-se é reconhecer-se culpado por uma violação de normas sociais e em débito com a pessoa ofendida. Nesse sentido, desculpar-se é um ato perigoso para a face do locutor. Consciente das ameaças que pairam sobre sua face, o locutor, no exemplo (4), se vale destas estratégias: evita a recusa explícita, antecede o pedido de desculpas por interjeição que, em língua portuguesa, expressa o sentido convencional de profunda tristeza ("Ai"), elabora um pedido de desculpas indireto (a justificativa), emprega o imperfeito ("queria") que, enquanto metáfora temporal (WEINRICH, 1973), atenua os efeitos de certeza, urgência e objetividade que provocaria o uso do presente ("quero"), estabelece uma relação de contra-argumento ("mas"), com a qual traz um argumento mais forte do que sua vontade de comparecer ao evento (a falta de dinheiro), utiliza o item lexical "real", que, nesse contexto, funciona como um modalizador intensificando o grau de adesão do locutor à verdade do que diz, sendo comutável por "de verdade", e, por fim, utiliza o emoji (carinha chorando). 
Nessa reação, o emoji também atua como um modalizador que reafirma o sentimento de profunda tristeza expresso inicialmente pela interjeição.

$\mathrm{O}$ acúmulo de estratégias de polidez nessa curta reação constitui um bom exemplo de como em nossa cultura o pedido de desculpas é um ato considerado altamente ameaçador para a face positiva do locutor. Nessa perspectiva, verificase que, assim como na esfera política (HARRIS; GRAINGER; MULLANY, 2006, KAMPF, 2008, 2009), a realização desse ato na comunicação digital coloca o locutor na situação delicada de dever se desculpar, mas sem expor excessivamente sua face a ataques.

O exemplo (4) permite verificar ainda a diferença entre respostas preferidas (aceitação do convite) e despreferidas (recusa do convite) em nosso corpus e como os emojis atuam nas diferentes reações. Após a realização do convite ("Mas gostaria mto q vcs fossem!"), dois locutores reagem, aceitando o convite. O primeiro utiliza apenas emojis (sequência de palmas), enquanto o segundo produz o enunciado "Estarei lá!". Como as duas reações são respostas preferidas ao convite, elas são formuladas de maneira direta e sucinta. Já o terceiro locutor se desculpa por não poder aceitar o convite e, como vimos, considera necessário utilizar uma série de estratégias de polidez com as quais, no final das contas, busca revelar que a responsabilidade por sua ausência no evento não é sua, mas da falta de dinheiro.

\section{CONSIDERAÇÕES FINAIS}

Neste estudo, nosso intuito foi revelar o papel de primeira importância que os emojis presentes em pedidos de desculpas exercem no trabalho de faces que ocorre na comunicação digital. Nesse contexto, os pedidos de desculpas de que fazem parte emojis constituem estratégia de reparo ou de restauração da imagem do ofensor e do ofendido. Isso porque, com essas desculpas, o ofensor explicita para o ofendido que reconhece que cometeu uma violação ou uma quebra de normas que regulam as relações sociais e que essa quebra precisa ser reparada. Ao mesmo tempo, com a desculpa elaborada de forma indireta e modalizada por emojis, o ofensor mostra ao ofendido que, apesar da ofensa cometida, ele, ofensor, ainda é uma pessoa que respeita as convenções que estruturam as relações sociais ou alguém com quem relações de amizade/proximidade podem ser mantidas. Do contrário, não teria reconhecido a culpa pela qual se desculpa.

Com base nas análises realizadas, foi possível extrair algumas funções mais gerais dos emojis enquanto estratégias de polidez na comunicação digital. Nesse tipo de comunicação, os emojis: 
- atuam como modificadores externos de pedidos de desculpas (geralmente) indiretos e, desse modo, exercem papel de modalizadores para as justificativas com as quais os locutores indiretamente se desculpam. Nessa função, os emojis pemitem ao locutor expressar descontentamento e embaraço pela recusa ao convite, recusa que costuma se materializar na forma de justificativas ou explicações. Assim, a sequência formada por recusa e emoji atua como importante estratégia de polidez que atenua o grau de agressividade das recusas para a face do produtor do convite;

- participam das estratégias de reparo, com as quais o locutor tenciona reparar a possível perda de sua face positiva, resultante da realização de um ato de fala despreferido, ou não esperado para a ocasião. Nesse sentido, os emojis expressam sentimentos (tristeza, constrangimento, embaraço etc.) que evidenciam a consciência do locutor de que ele infringiu determinada norma social (convites devem ser aceitos) e de que se lamenta por isso. Como as análises revelaram, sem o emoji, mesmo as desculpas indiretas soam excessivamente ríspidas. Mas, com o emoji, o locutor evidencia reconhecer que sua recusa implica uma quebra de normas sociais tacitamente acordadas e, consequentemente, um ataque à face do interlocutor;

- atuam como elementos proxêmicos, aproximando os interlocutores e minimizando os efeitos nocivos de uma recusa a um convite. Por isso, os emojis reforçam o sentimento de pertencimento a um grupo social específico, sendo utilizados para mitigar ameaças de face potenciais, ou em curso. Essa função se explica pelo fato de que, com o emoji, o locutor pode evitar a criação, manutenção ou intensificação de uma interação polêmica (KERBRAT-ORECCHIONI, 1992, AMOSSY, 2014), revelando que, ao se consternar por uma recusa, os elos sociais que o ligam aos demais membros do grupo estão mantidos ou não sofreram abalo.

Tendo em vista os resultados alcançados nesta pesquisa e as funções sistematizadas acima, com base em nossas análises, é importante ressaltar que os emojis circunscrevem a troca comunicativa digital a um ambiente de informalidade, reforçando a proximidade entre os interlocutores. Eles contribuem, assim, para que o fluxo comunicativo harmônico não seja interrompido, bem como atuam como elementos de cooperação discursiva, ligados ao desejo de sermos socialmente aceitos e de termos nossa imagem aprovada pelo outro.

Por isso, considerando que a comunicação digital está presente em diferentes domínios de nossa vida (profissional, escolar, religiosa, familiar, midiática etc.) e que nesse tipo de comunicação é massiva a utilização dos emojis, entendemos que os resultados ora apresentados, por auxiliarem na compreensão desse tipo de comunicação, têm o potencial de fomentar pesquisas que investiguem as especificidades do uso dos emojis nesses diferentes domínios. A essas pesquisas 
futuras cabem as tarefas de investigar, por exemplo, as diferenças e semelhanças de funções de um mesmo emoji em domínios distintos, as nuances de sentido produzidas pelas ocorrências de emoji modificando a força ilocucionárias de atos de fala diversos (ordens, promessas, críticas, elogios etc.), o modo como os mesmos emojis são utilizados em diferentes comunidades de usuários da língua, para alcançarem objetivos comunicativos variados, o papel dos emojis na construção do consenso ou do dissenso entre interlocutores etc. Essas perspectivas de estudos apontam para seu potencial pedagógico, na medida em que podem embasar uma reflexão em sala de aula sobre um recurso de linguagem intensamente usado pelos estudantes dos diferentes níveis do ensino, reflexão que os leve a perceber os contextos de uso e as multiplicidades funcionais dos emojis.

\section{$\overline{\text { REFERÊNCIAS }}$}

AIJMER, K. (1996). Conversational routines in English. Convention and creativity. London: Longman.

AMOSSY, R. (2014). Apologie de la polémique. Paris: Presses universitaires de France.

AUSTIN, J. L. (1990). Quando dizer éfazer. Porto Alegre: Artes Médicas.

AVELAR, F. T. (2018). A pragmática dos emojis. Dissertação de Mestrado em Linguística. Faculdade de Letras, UFMG, Belo Horizonte.

BLUM-KULKA, S.; OLSHTAIN, E. (1984). Requests and apologies: a cross-cultural study of speech act realization patterns (CCSARP). Applied Linguistics, v. 5, n. 3, pp. 196-212.

BLUM-KULKA, S.; HOUSE, J.; KASPER, G. (orgs.). (1989). Cross-cultural pragmatics: requests and apologies. Norwood, NJ: Ablex.

BROWN, P.; LEVINSON, C. (1978). Universals in language usage: Politeness phenomena. Questions and politeness: Strategies in social interaction. Cambridge University Press.

BROWN, P; LEVINSON, S. (1987). Politeness: some universals in language use. Cambridge: Cambridge University Press.

CRYSTAL, D. (2006). Language and the Internet. Cambridge: Cambridge University Press. 
CULPEPER, J. (2011). Impoliteness: Using Language to Cause Offence. Cambridge: Cambridge University Press.

CUNHA, G. X.; RUFINO, J. A. (2018). Deus lhe pague: o agradecimento como estratégia de protesto na canção de Chico Buarque. Cadernos de Linguagem e Sociedade, v. 19, pp. $112-131$.

DRESNER, E; HERRING S. (2010). Functions of the Nonverbal in CMC. Emoticons and Illocucionary Force. Cambridge: Cambridge University Press.

EVANS, V. (2017). The Emoji Code: how smiley faces, love hearts and thumbs up are changing the way we communicate. London: Michael O’Mara Books.

GIVÓN, T. (2014). On understanding grammar. London: Academic Press.

GOFFMAN, E. (1973). La mise em scène de la vie quotidienne: les relations em public. v. 2. Paris: Les Éditions de Minuit.

GOFFMAN, E. (1983). The interaction order. American Sociological Review, v. 48, pp. 1-17.

GOFFMAN, E. (2011). Ritual de interação: ensaiossobre o comportamento face a face. Petrópolis: Vozes.

HARRIS, S.; GRAINGER, K.; MULLANY, L. (2006). The pragmatics of political apologies. Discourse \& Society, v. 17, n. 6, pp. 715-737.

HERITAGE, J.; RAYMOND, C. W. (2016). Are explicit apologies proportional to the offenses they address? Discourse Processes, v. 53, n. 1-2, pp. 5-25.

HOLMES, J. (1990). Apologies in New Zealand English. Language in society, v. 19, n. 2, pp. 155-169.

KAMPF, Z. (2008). The pragmatics of forgiveness: judgment of apologies in the Israeli political arena. Discourse \& Society, v. 19, n. 5, pp. 577-598.

KAMPF, Z. (2009). Public (non-)apologies: the discourse of minimizing responsibility. Journal of Pragmatics, v. 41, pp. 2257-2270.

KELLY, R.; WATTS, L. (2015). Characterising the inventive appropriation of emoji as relationally meaningful in mediated close personal relationships. Experiences of Technology Appropriation: unanticipated users, usage, circumstances, and Design. Amsterdam, p. 198-212. 
Disponível em: <

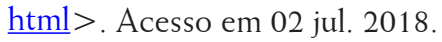

KERBRAT-ORECCHIONI, C. (1992). Les interactions verbales. Paris: Colin.

KERBRAT-ORECCHIONI, C. (2001). Les actes de langage dans le discours: théorie et fonctionnement. Paris : Nathan.

KERBRAT-ORECCHIONI, C. (2006). Análise da conversação: princípios e métodos. São Paulo: Parábola Editorial.

LAKOFF, R. T. (2001). Nine ways of looking at apologies: the necessity for interdisciplinary theory and method in discourse analysis. In: Schiffrin, D.; Tannen, D.; Hamilton, H. E. (orgs.). The bandbook of discourse analysis. Oxford: Blackwell, pp. 199-214.

LEECH, G. (2014) The pragmatics of politeness. Oxford: Oxford University Press.

LUTZKY, U.; KEHOE, A. (2017). "Oops, I didn't mean to be so flippant": a corpus pragmatic analysis of apologies in blog data. Journal of Pragmatics, v. 116, pp. 27-36.

MEIER, A. J. (1995). Passages of politeness. Journal of Pragmatics, v. 24, pp. 382-392.

MEIER, A. J. (1998). Apologies: what do we know? International Journal of Applied Linguistics, v. 8, n. 2, pp. 215-231.

OLIVEIRA, A. L. A. M.; CARNEIRO, M. M. (2018). Sobre o potencial semântico pragmático das hashtags In: Cunha G. X.; Oliveira, A. L. A. M. (orgs.) Múltiplas perspectivas do trabalho de face nos estudos da linguagem. Belo Horizonte: FALE/POSLIN/ UFMG, pp. 207-226.

PAIVA, V. L. M. O. (2016). A linguagem dos emojis. Trabalhos em Linguística Aplicada, v. 55, n. 2, pp. 379-399.

PAVALANATHAN, U.; EISENSTEIN, J. (2015). Emoticons vs. Emojis on twitter: a causal inference approach. Association for the Advancement of Artificial Intelligence. Cambridge: Cambridge University Press.

ROSBORG, A. (1995). Interlanguage pragmatics. Requests, complaints and apologies. Berlin: Mouton de Gruyter.

SEARLE, J. R. (1969). Speech acts. An essay in the philosophy of language. Cambridge: Cambridge University Press. 
SHISHAVAN, H. B.; SHARIFIAN, F. (2016). The refusal speech act in a cross-cultural perspective: a study of Iranian English-language learners and Anglo-Australian speakers. Language \& Communication, v. 47, pp. 75-88.

WEINRICH, H. (1973). Le temps. Paris: Éditions du Seuil.

WERNECK, A. (2012). A desculpa: as circunstâncias e a moral das relações sociais. Rio de Janeiro: Civilização Brasileira.

WILSON, D.; SPERBER, D. (2002). Relevance theory. Handbook of pragmatics. Blackwell.

Recebido: 2/09/2018

Aceito: 21/10/2018 